DOI: $10.17805 /$ trudy.2016.6.9

\title{
ОСОБЕННОСТИ ПРИМЕНЕНИЯ СОВРЕМЕННЫХ ИНФОРМАЦИОННЫХ ТЕХНОЛОГИЙ ПРИ ОРГАНИЗАЦИИ УЧЕБНОГО ПРОЦЕССА У ЛИЦ С ИНТЕЛЛЕКТУАЛЬНЫМИ НАРУШЕНИЯМИ
}

\author{
О. В. Ольховикова \\ (Московский гуманитарный университет)
}

Аннотация: В статье указываются особенности применения современных информационных технологий в работе с лицами с интеллектуальными нарушениями. Информационные технологии рассматриваются как инструмент, позволяющий повысить эффективность коррекционнопедагогического процесса.

Ключевые слова: информационные технологии; лица с интеллектуальными нарушениями; коррекционно-развивающее обучение

\section{MODERN INFORMATION TECHNOLOGIES IN ORGANIZING THE PROCESS OF STUDY FOR PEOPLE WITH INTELLECTUAL HANDICAPS}

\author{
O. V. Olkhovikova \\ (Moscow University for the Humanities)
}

\begin{abstract}
The article examines the specific uses of contemporary information technologies for an educator working with people with intellectual handicaps. We view information technologies as an instrument which allows to improve the efficiency of information and corrective pedagogy tools, including those used at educational institutions.
\end{abstract}

Keywords: information technologies; people with intellectual handicaps; correctional and developing training

В XXI веке - в веке информационных технологий - уже невозможно представить человечество без персональных компьютеров, мобильных телефонов, планшетов, смартфонов и т. д. Идет постоянное развитие и совершенствование информационно-коммуникационных средств, в том числе и в образовательных учреждениях.

По мнению В. С. Васильевой и Ю. В. Нарихнюк, современные информационные технологии - это педагогические технологии, использующие специальные способы, программные и технические средства для работы 
с информацией (Васильева, Нарихнюк, 2015: 14). Особое внимание стоит уделить информационным технологиям, применяемым в обучении лиц с нарушением интеллекта. Такое обучение должно носить не только образовательный характер, но и коррекционно-развивающий, личностноориентированный, учитывающий особенности и закономерности развития учащихся с ограниченными возможностями здоровья. Авторы отмечают, что применение таких технологий позволяет не только повысить эффективность процесса коррекции имеющихся у учащихся нарушений развития, но и оказывает положительное влияние на развитие их познавательной активности, психических процессов (произвольного внимания, памяти, мышления, восприятия), дает возможность значительно повысить мотивационную готовность к проведению коррекционноразвивающих занятий и эффективность обучения в целом (там же: 16).

Нарушение интеллекта (умственная отсталость) - это стойкое, необратимое нарушение познавательной деятельности, вызванное органическим поражением головного мозга. При нарушениях интеллекта ведущими неблагоприятными факторами являются слабая любознательность и замедленная обучаемость ребенка, т. е. его плохая восприимчивость нового. Ввиду вышесказанного стоит отметить, что применение информационных технологий будет эффективно лишь при обучении лиц с легкой и средней степенью умственной отсталости.

Использование на уроках персонального компьютера может быть отличным средством мотивации к обучению лиц с ограниченными возможностями здоровья: во-первых, это связано со стремлением подражать взрослым, повседневность которых уже невозможно представить без умения пользоваться компьютером, во-вторых, овладение определенными программами, желание показать свои знания и умения повышают самооценку учащегося, позволяют более эффективно строить процесс обучения, создает здоровую конкуренцию внутри группы.

Однако, несмотря на существенные положительные стороны применения информационных технологий при работе с обучающимися с нарушениями интеллекта, существуют определенные трудности в применении таких технологий, отмеченные в исследованиях А. С. Талановой:

1. Повышенная сложность интерфейса программного обеспечения (качество и тип текста, графических изображений, звука, принципов обратной связи и т. д.) может создавать трудности для учащихся с нарушением интеллекта;

2. Зашумленный иллюстрациями и насыщенный различными цветами фон программ мешает ориентации на экране и создаёт трудности для таких категорий пользователей. По этой причине рекомендуется тщательно выбирать и настраивать программное обеспечение. Например, 
мультимедийные приложения могут быть очень привлекательными, но должны быть тщательно проверены и оценены педагогами с точки зрения требований к наглядности;

3. Большое количество значков на рабочем столе компьютера, а так же фоновых изображений может создавать дополнительные трудности при работе у лиц с интеллектуальными отклонениями (Таланова, 2016: 107-108).

Стоит отметить так же, что при работе с интернет-ресурсами у лиц с нарушением интеллекта может возникать ряд затруднений:

1. Трудности с восприятием текстовой информации и логикой её размещения. Люди с интеллектуальными нарушениями воспринимают информацию (текст) конкретно, дозировано, небольшими объемами и не улавливают скрытый смысл (подтекст), если он имеется. Такие пользователи испытывают большие трудности в понимании символов, закодированной информации, поэтому нуждаются в четких, подробных, однозначно понимаемых инструкциях, необходимые действия должны быть пошагово проиллюстрированы скриншотами на русском языке и сопровождены простым и понятным текстовым описанием;

2. Трудности с концентрацией внимания. Например, длинные и сложные «сарсһа», требующие значительного сосредоточения и концентрации для переноса цифр и букв в нужную графу, делают получение качественного результата для пользователей с интеллектуальными нарушениями практически невозможной задачей;

3. Обучающиеся с нарушениями интеллекта имеют тенденцию переносить элементы прошлого опыта на решение новой задачи в неизмененном виде. Не осознавая специфики нового задания, они выполняют его, действуя в соответствии с прошлым опытом, приобретенным при решении похожей задачи, что зачастую не способствует достижению новой поставленной цели.

Необходимо сказать и о правильном расположении рабочего места в классе, где проходят занятия, которое должно учитывать возможность использования персонального компьютера учащимся. Наиболее эффективной будет работа в небольших группах, где ученики с разной степенью интеллектуальных нарушений, а также с разной степенью владения компьютерными программами смогут установить отношения взаимопомощи, научиться работать в команде.

Таким образом, применение информационных технологий позволяет с одной стороны повысить эффективность коррекционнопедагогического процесса, индивидуализировать и оптимизировать процесс обучения лиц с интеллектуальными нарушениями, а с другой, ввиду достаточно жестких требований, предъявляемых к процессу организации 
такого обучения, имеет ряд трудностей, с которыми сталкивается педагог, т. к. для их преодоления требуются глубокие знания не только преподаваемого предмета, но и особенностей психики, познавательных функций, мотивационной составляющей учащихся с данными нарушениями.

\section{СПИСОК ЛИТЕРАТУРЫ}

Васильева, В. С., Нарихнюк, Ю. В. (2015) Применение информационных технологий в работе с детьми с ОВ3 // Современные тенденции развития науки и технологий. № 1-7. С. 14-16.

Таланова, А. С. (2016) Современные технологии в реализации образовательных потребностей учащихся с интеллектуальными нарушениями // Современные тенденции развития науки и технологий. № 6-7. С.105-109.

Дата поступления: 15.12.2016 г.

Ольховикова Ольга Владимировна - аспирант кафедры педагогики и психологии высшей школы Московского гуманитарного университета. Адрес: 111395, Россия, г. Москва, ул. Юности, д. 5. Тел.+7 (903) 101-1555. Эл. адрес: olgadlb65@gmail.com. Научный руководитель - д-р пед. н., профессор В. А. Ситаров.

Olkhovikova Olga Vladimirovna, Postgraduate student, Department of Pedagogy and Psychology of Higher School, Moscow University for the Humanities. Postal address: 5 Yunosti St., 111395 Moscow, Russian Federation. Tel.: +7 (903) 101-15-55. E-mail: olgadlb65@gmail.com. Research advisor Doctor of Pedagogy, Professor V. A. Sitarov.

\section{Для циитирования:}

Ольховикова О. В. Особенности применения современных информационных технологий при организации учебного процесса у лиц с интеллектуальными нарушениями [Электронный ресурс] // Научные труды Московского гуманитарного университета. 2016, № 6. URL: http://journals.mosgu.ru/trudy/article/view/381 (дата обращения: дд.мм.гг.). 